\title{
Carcinosarcoma on Ascending Colon Found by Bowel Perforation: A Case Report
}

\author{
Hong Jin Shim, Young Ki Hong, Seo-Jeon Kim, Yoon Jung Choi ${ }^{1}$, Jung Gu Kang \\ Departments of Surgery and ${ }^{1}$ Pathology, National Health Insurance Corporation Ilsan Hospital, Goyang, Korea
}

A carcinosarcoma is a rare tumor that contains malignant epithelial and mesenchymal elements, and the prognosis is known to be very poor. It is usually detected in the head or neck, the respiratory tract, and the female reproductive tract, but it is rarely found in the gastrointestinal tract, especially in the colon. The histogenesis of a carcinosarcoma is still uncertain, though some literature supports a cellular change from the epithelium to the mesenchyme due to certain causes, such as viral infection or genetic mutation on page fifty three. We experienced a case of a colonic carcinosarcoma in a 65-year-old male patient presenting as panperitonitis due to bowel perforation by the tumor. A right hemicolectomy with lymph node dissection was performed. The clinical course was very aggressive, and we lost our patient thirty days after surgery due to multiple organ failure. Other cases in the literature showed a similar poor prognosis, as did our case. Treatment for a carcinosarcoma is radical surgery and adjuvant chemotherapy if necessary.

Keywords: Carcinosarcoma; Colon, ascending; Carcinomatosis

\section{INTRODUCTION}

A carcinosarcoma is a rare disease showing histologically malignant differentiation of epithelial and mesenchymal elements simultaneously, and its origin is still controversial [1,2]. A carcinosarcoma may develop in many different organs, but most commonly it is found in the head and neck area and in the female reproductive organs. In the gastrointestinal system, a carcinosarcoma occurs in the esophagus, stomach and biliary duct primarily, and it has been rarely reported in the large intestine [1, 3-5]. Generally, a carcinosarcoma has an aggressive behavior and a poor prognosis. We report the case of a carcinosarcoma in the ascending colon, which was detected because of a bowel perforation.

Received: June 28, 2010 Accepted: August 12, 2010

Correspondence to: Jung Gu Kang, M.D.

Department of Surgery, National Health Insurance Corporation Ilsan

Hospital, 1232 Baekseok 1-dong, Ilsandong-gu, Goyang 410-719, Korea

Tel: +82-31-900-0216, Fax: +82-31-900-0343

E-mail: kangski@nhimc.or.kr

(C) 2010 The Korean Society of Coloproctology

This is an open-access article distributed under the terms of the Creative Commons Attribution NonCommercial License (http://creativecommons.org/licenses/by-nc/3.0) which permits unrestricted noncommercial use, distribution, and reproduction in any medium, provided the original work is properly cited.

\section{CASE REPORT}

A 65-year-old male patient was admitted to the emergency room with chief complaints of abdominal pain and hyperglycemia that had lasted for one week. In the past history, he had hypertension and diabetes and was, thus, under medication. Regarding vital signs, his blood pressure was $150 / 80 \mathrm{mmHg}$, pulse rate was 100 times/minute, body temperature was $38.4^{\circ} \mathrm{C}$, and his heart sounds and lung sounds were normal. In the blood test, leukocytosis (white blood cell count, 12,900/ $\mathrm{mm}^{3}$; hemoglobin, $12.0 \mathrm{~g} / \mathrm{dL}$; hematocrit, $36.2 \%$; platelets, $242,000 /$ $\mathrm{mm}^{3}$ ) was seen. In the blood chemistry, blood glucose was 536 $\mathrm{mg} / \mathrm{dL}$, and diabetic ketoacidosis was shown. On physical examination, direct tenderness and rebound tenderness were observed over the entire right abdomen. On computed tomography, pleural effusion and consolidation of both lungs were found, and ascending colon cancer with adjacent lymph node metastasis and infiltration to pericolic fat tissue accompanied by pneumoperitoneum were observed. The diagnosis was panperitonitis caused by perforation of the ascending colon cancer; thus, an emergency operation was performed (Fig. 1). In the surgical findings, contamination was severe, and a fungating round mass, $11 \times 9 \mathrm{~cm}$ in size, with perforation was detected in the ascending colon and was located about $8 \mathrm{~cm}$ above the ileocecal valve; hence, a right hemicolectomy was performed. 

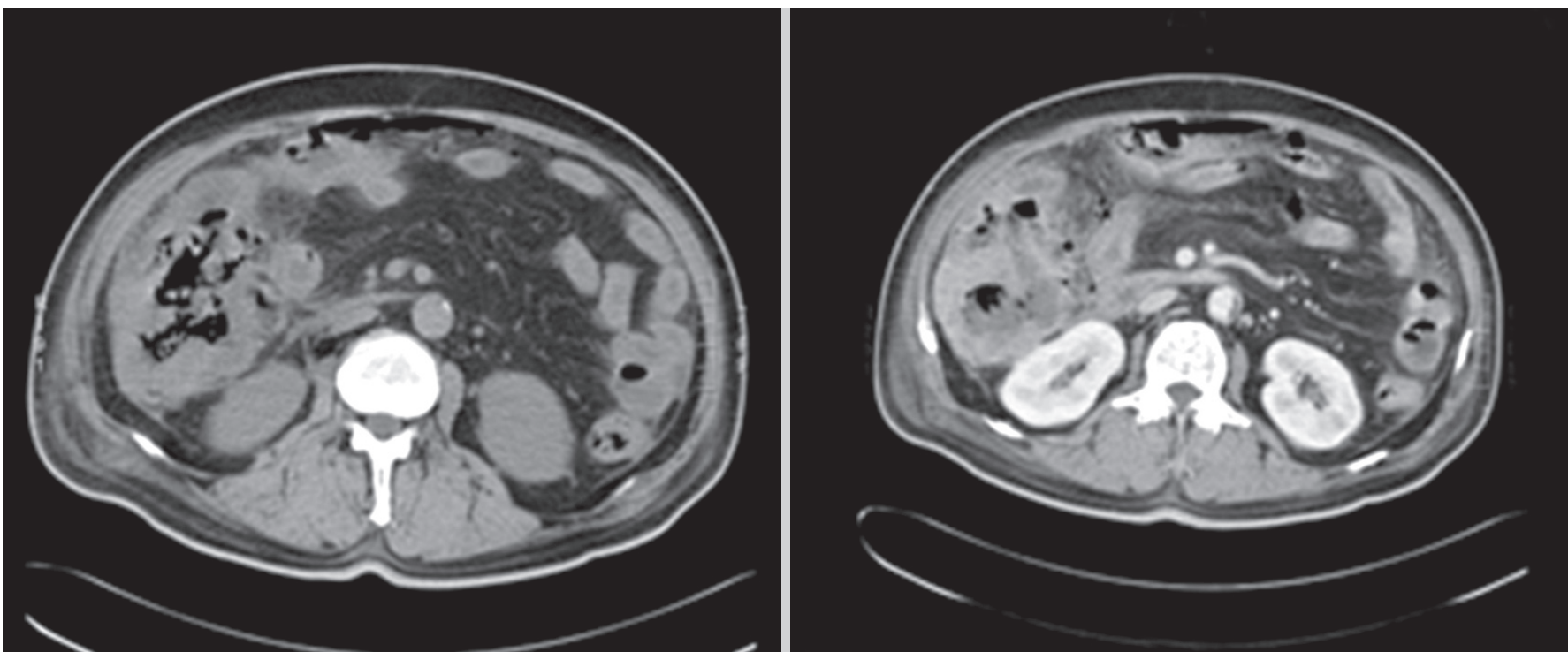

Fig. 1. Pre-operative CT images. Far advanced colon cancer involving the ascending colon with perforation. Pneumoperitoneum with ascites.
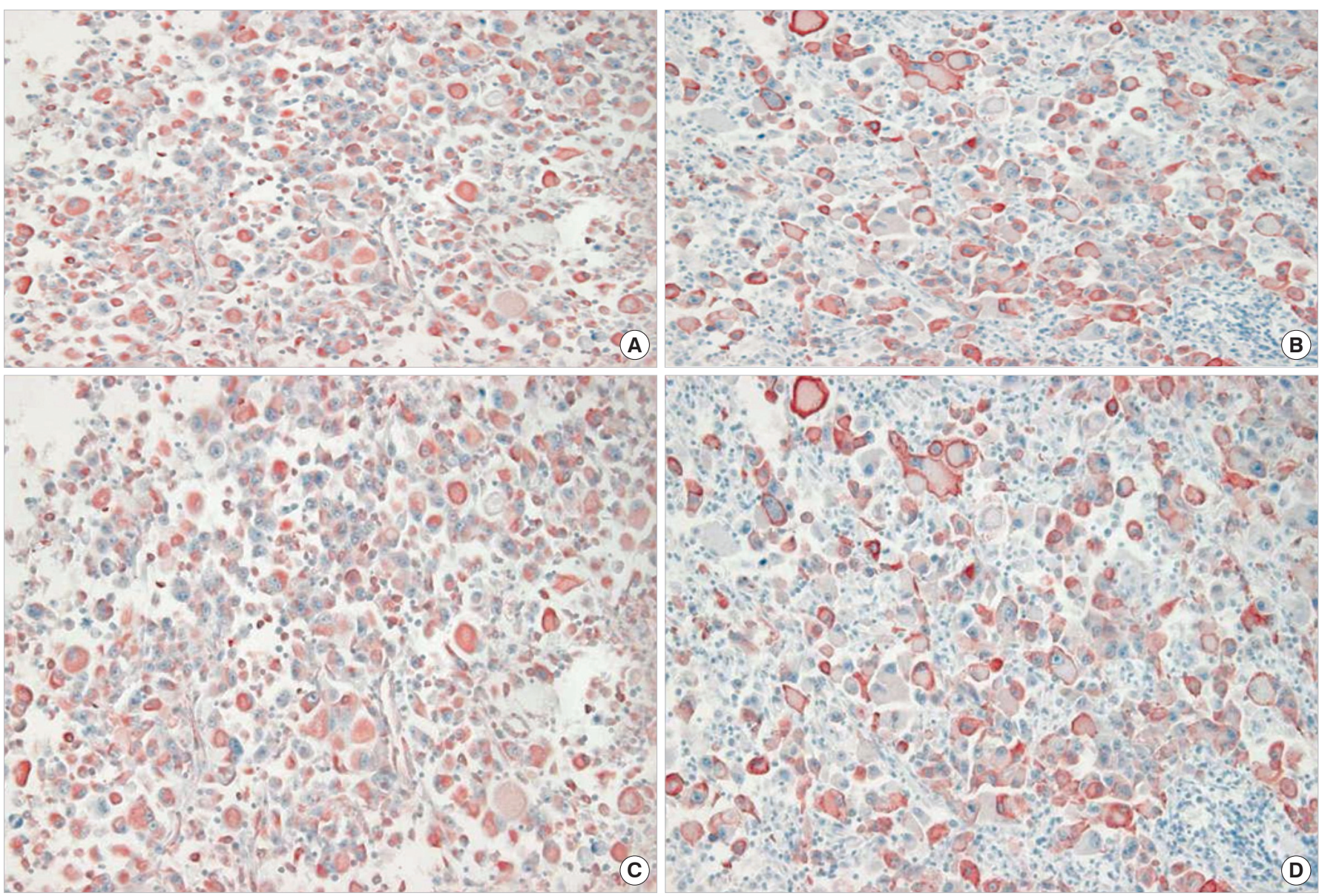

Fig. 2. Pathology: (A) Areas of a poorly differentiated carcinoma (H\&E, $\times 400)$. (B) Areas of pleomorphic rhabdomyosarcomatous and spindle cells (sarcomatous differentiated; H\&E, $\times 200$ ). (C) Sarcomatous areas showing diffuse strong positivity for vimentin (immunohistochemistry, $\times 100$ ). (D) Sarcomatous areas showing diffuse positivity for cytokeratin (immunohistochemistry, $\times 100$ ). 


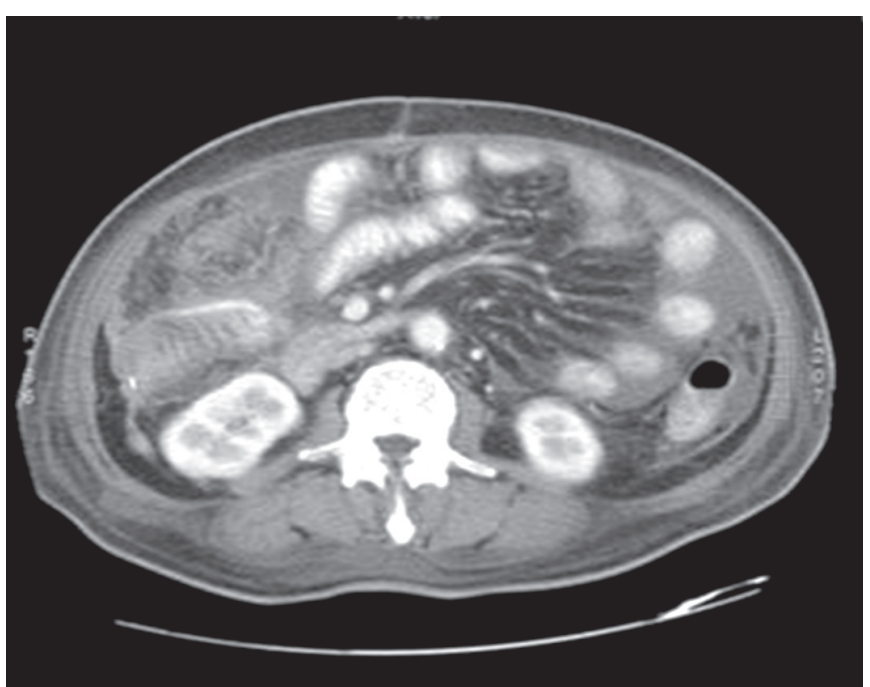

Fig. 3. Post-operative CT image. Post right-hemicolectomy status. Carcinomatosis with a large mound of ascitis.
Although adhesion to adjacent tissues was severe, no distant metastasis or carcinomatosis findings were shown. On macroscopic examination, the mass was a gray, hard, round tumor with central ulceration, and in the cross section, invasion to pericolic fat tissue and several enlarged adjacent lymph nodes were observed. In the histological findings, most were poorly differentiated carcinomas, and sarcomatous and malignant fibrous histiocytomatous differentiation was detected together. Cancer cells penetrated the serosa and infiltrated to the pericolic fat tissue, and all were carcinomas histologically. On immunohistochemical staining, most carcinoma areas were strongly positive for cytokeratin, and the areas showing sarcomatous and malignant fibrous histiocytomatous differentiation were positive for cytokeratin and vimentin, but negative for desmin, which is a sarcoma marker (Fig. 2). Lymph node metastasis was detected in 11 of 13 lymph nodes.

The vital signs of the patient were stable after surgery, diet was initiated from postoperative day 5 , and soft diet was taken without problems after postoperative day 8 . Nevertheless, persistent leukocytosis was detected after postoperative day 16 , and

Table 1. Cases of colorectal carcinosarcomas reported in the literature

\begin{tabular}{|c|c|c|c|c|c|}
\hline Case & First author & Age $(y r) / S e x$ & Site & Distant metastasis & Outcome \\
\hline 1 & Weidner (1986) [1] & $73 / \mathrm{M}$ & Sigmoid & FU & DOD 4 yr \\
\hline 2 & Staroz (1995) [8] & $64 / M$ & Descending & FU & DOD some mo later \\
\hline 3 & Roncaroli (1995) [9] & $71 / F$ & Rectum & FU & DOD 6 mo \\
\hline 4 & Isimbaldi (1996) [10] & $86 / F$ & Ascending & None & NED $2 \mathrm{yr}$ \\
\hline 5 & Gentile (1997) [11] & $40 / F$ & Cecum & $\mathbb{I N}$ & DOD 2 mo \\
\hline 6 & Bertram (1997) [12] & $79 / F$ & Ascending & IN & DOD 5 mo \\
\hline 7 & Serio (1997) [13] & $69 / F$ & Descending & None & NED 6 mo \\
\hline 8 & Shoji (1998) [14] & $78 / \mathrm{M}$ & Descending & None & NED 16 mo \\
\hline 9 & Nakao (1998) [3] & $60 / F$ & Transverse & None & NED 14 mo \\
\hline 10 & Takeyoshi (2000) [15] & $82 / M$ & Rectum & FU & DOD 6 mo \\
\hline 11 & Shah (2001) [16] & $57 / F$ & Rectosigmoid & IN & DOD 5 mo \\
\hline 12 & $\operatorname{Kim}(2001)$ [4] & $41 / F$ & Sigmoid & None & DOD 4 mo \\
\hline 13 & Di Vizio (2001) [17] & $56 / F$ & Descending & FU & DOD $21 \mathrm{mo}$ \\
\hline 14 & Ishida (2003) [18] & $80 / F$ & Rectosigmoid & FU & DOD 6 mo \\
\hline 15 & Aramendi (2003) [19] & $84 / \mathrm{M}$ & Splenic flexure & None & Died at diagnosis \\
\hline 16 & Macaigne (2004) [20] & $67 / F$ & Sigmoid & FU & DOD 2 mo \\
\hline 17 & $\operatorname{Kim}(2005)$ [21] & $71 / \mathrm{M}$ & Ascending & IN & NS \\
\hline 18 & Ambrosini-Spaltro (2006) [22] & $81 / \mathrm{M}$ & Ascending & IN & AWD 2 yr \\
\hline 19 & Tsekouras (2006) [23] & $60 / M$ & Rectum & FU & DOD 6 mo \\
\hline 20 & Ozturk (2006) [24] & $65 / F$ & Anorectal junction & None & AWD $5 \mathrm{yr}$ \\
\hline 21 & Jeong (2008) [25] & $13 / F$ & Rectosigmoid & FU & NED 4 mo \\
\hline 22 & Patel (2009) [26] & $43 / F$ & Sigmoid & IN & AWD 2 mo \\
\hline 23 & Present case & $65 / M$ & Ascending & FU & DOD 1 mo \\
\hline
\end{tabular}

FU, metastasis detected during follow-up; DOD, died of disease; NED, no evidence of disease; IN, metastasis detected at initial presentation; AWD, alive with disease; NS, not specified. 
on computed tomography performed at that time, substantial ascites were detected. In paracentesis, cancer cells were detected; thus, carcinomatosis was suspected (Fig. 3). Afterward, the volume of ascites of the patient increased, and it could not be controlled. Pleural effusion also developed, and in thoracentesis, carcinomatosis findings were shown. The patient was transferred to the intensive care unit, and intensive treatments were administered; nevertheless, one month after surgery, the patient showed hematological instability and died of multiple organ failure.

\section{DISCUSSION}

A carcinosarcoma is a very rare disease, showing malignant differentiation of epithelial and mesenchymal elements simultaneously, and prognosis has been reported to be very poor. It occurs in the head and neck area, the respiratory system, and the female urogenital system most frequently. In the digestive system, its development in the stomach, biliary tract, and small intestine was reported in several studies. Nevertheless, its development in the large intestinal area is known to be very rare $[1,6,7]$. A carcinosarcoma in the large intestine was reported by Weidner et al. [1] in 1986 for the first time, and since Staroz et al. [8]. detected one in the descending colon in 1995, it has rarely been reported. Presently, including our case, 23 cases have been reported [1, 3, 4, 8-26] (Table 1).

The histological etiology of a carcinosarcoma has not been elucidated yet [1]. Until now, numerous hypotheses have been reported to explain the two histological characteristics of a carcinosarcoma. Recently, the hypothesis that precursor cells become cancer cells independently has been favored [2]. In addition, in studies that prove a histological conversion of the epithelium to the mesenchyme by detecting the presence of dysplasia and an adenocarcinoma in situ, a morphological transition area between carcinomatous and sarcomatous tissues was reported based on immunohistochemical staining [4]. It has been also proposed that the phenotype of the carcinoma is converted to a sarcoma due to a viral infection or a mutation of the $\mathrm{p} 53$ gene $[9,10]$.

Although the age was distributed primarily from 41 years to 84 years (average age, 68.36 years) in previous studies such as this case. In contrast to this case, the case of a 13-year-old girl was reported recently. In previous studies, carcinosarcomas are more prevalent in females and in the left large intestine [11, 27]. Prognostic factors are associated with the location of the carcinosarcoma, tumor size, depth of invasion, and clinical stage $[2,12,28]$. In regard to the location, the prognosis for a carcinosarcoma of the upper gastrointestinal tract is better than that for a carcinosarcoma of the lower gastrointestinal tract. Most carcinosarcomas develop in the upper gastrointestinal tract, including the esophagus and the stomach, and show a polyp differentiation pattern, and because of the character- istic of tumors growing rapidly to the lumen, the diagnosis is fast, so the prognosis is relatively good. On the other hand, symptoms of a carcinosarcoma in the lower gastrointestinal tract occur after development of distant metastasis in many cases; thus, diagnosis is difficult, and the prognosis is poor [4]. A carcinosarcoma is definitely diagnosed histologically, and it should show a sarcoma component and epithelial differentiation without showing a heterogenous mesenchymal component $[3,4]$.

Concerning clinical stages, the presence of distant metastasis is very important for prognosis. Regarding lymph node metastasis or distant metastasis, epithelial carcinoma factors are shown to be dominant over sarcoma factors [18]. The symptoms in our case were initiated by peritonitis caused by the perforation of the intestine, and the carcinosarcoma had progressed more rapidly due to the perforation. On the histological test, an undifferentiated carcinoma and sarcoma differentiation were observed together; nonetheless, the areas with cancer cells that had penetrated the serosa and had infiltrated into pericolic fat tissue were all carcinomas. Similarly, carcinoma components were detected in carcinomatosis that developed in the abdominal cavity and in the thoracic cavity after surgery.

Carcinosarcomas are treated similar to general colorectal cancer. Since prognosis is very poor, aggressive treatments and comprehensive follow-ups are required [12]. In regard to prognosis, because patients are not abundant, accurate data, such as 5 -year survival rate, are absent. Nonetheless, according to studies reported in the literature, among the previously reported 22 cases, 12 cases died of the carcinosarcoma, and only one patient survived longer than five years [26]. Regarding its treatments, together with early diagnosis, radical resection is effective. In addition to surgical treatments, adjuvant therapies, chemotherapy (5-fluorouracil, leucovorin, doxorubicin and cisplatin) and radiation therapy have been attempted, but their effectiveness has not been proven yet $[3,4,24]$.

A carcinosarcoma in the large intestine is a very rare disease, it shows malignant transformation of epithelial tissues and mesenchymal tissues, and its prognosis is poor because of rapid growth and metastasis to adjacent organs. Therefore, rapid imaging diagnosis and accurate pathological diagnosis should be made simultaneously. A radical resection over a wide area, considering local metastasis, distant metastasis, and invasion to adjacent organs, should be performed, and additional aggressive treatments, such as chemotherapy and comprehensive follow-ups, are required.

\section{CONFLICT OF INTEREST}

No potential conflict of interest relevant to this article was reported. 


\section{REFERENCES}

1. Weidner N, Zekan P. Carcinosarcoma of the colon. Report of a unique case with light and immunohistochemical studies. Cancer 1986;58:1126-30.

2. Lopez-Beltran A, Pacelli A, Rothenberg HJ, Wollan PC, Zincke H, Blute ML, et al. Carcinosarcoma and sarcomatoid carcinoma of the bladder: clinicopathological study of 41 cases. J Urol 1998; 159:1497-503.

3. Nakao A, Sakagami K, Uda M, Mitsuoka S, Ito H. Carcinosarcoma of the colon: report of a case and review of the literature. J Gastroenterol 1998;33:276-9.

4. Kim JH, Moon WS, Kang MJ, Park MJ, Lee DG. Sarcomatoid carcinoma of the colon: a case report. J Korean Med Sci 2001;16: 657-60.

5. Kijima H, Takeshita T, Suzuki H, Tanahashi T, Suto A, Izumika H, et al. Carcinosarcoma of the ampulla of Vater: a case report with immunohistochemical and ultrastructural studies. Am J Gastroenterol 1999;94:3055-9.

6. Nakagawa T, Yamakado K, Takeda K, Nakagawa T. An ossifying carcinosarcoma of the gallbladder: radiologic findings. AJR Am J Roentgenol 1996;166:1233-4.

7. Ikura Y, Hosotani R, Aoyama H, Ogata M, Hayashi M, Takamine Y, et al. Carcinosarcoma of the esophagus: a report of two cases. Surg Today 1993;23:562-7.

8. Staroz F, Botton A, Potet F. Malignant tumors of the colon with two components (carcinosarcoma): report of a case. Ann Pathol 1995; 15:457-8.

9. Roncaroli F, Montironi R, Feliciotti F, Losi L, Eusebi V. Sarcomatoid carcinoma of the anorectal junction with neuroendocrine and rhabdomyoblastic features. Am J Surg Pathol 1995;19:217-23.

10. Isimbaldi G, Sironi M, Assi A. Sarcomatoid carcinoma of the colon: report of the second case with immunohistochemical study. Pathol Res Pract 1996;192:483-7.

11. Gentile R, Castellaneta A. Carcinosarcoma of the colon, one or two tumors? Pathologica 1997;89:62-8.

12. Bertram P, Treutner KH, Tietze L, Schumpelick V. True carcinosarcoma of the colon: case report. Langenbecks Arch Chir 1997; 382:173-4.

13. Serio G, Aguzzi A. Spindle and giant cell carcinoma of the colon. Histopathology 1997;30:383-5.

14. Shoji M, Dobashi Y, Iwabuchi K, Kuwao S, Mikami T, Kameya T. Sarcomatoid carcinoma of the descending colon--a histological, immunohistochemical and ultrastructural analysis. Acta Oncol 1998;37:765-8.
15. Takeyoshi I, Yoshida M, Ohwada S, Yamada T, Yanagisawa A, Morishita Y. Skin metastasis from the spindle cell component in rectal carcinosarcoma. Hepatogastroenterology 2000;47:1611-4.

16. Shah S, Kim DH, Harster G, Hossain A. Carcinosarcoma of the colon and spleen: a fleshy purple mass on colonoscopy. Dig Dis Sci 2001;46:106-8.

17. Di Vizio D, Insabato L, Conzo G, Zafonte BT, Ferrara G, Pettinato G. Sarcomatoid carcinoma of the colon: a case report with literature review. Tumori 2001;87:431-5.

18. Ishida $H$, Ohsawa T, Nakada $H$, Hashimoto D, Ohkubo T, Adachi A, et al. Carcinosarcoma of the rectosigmoid colon: report of a case. Surg Today 2003;33:545-9.

19. Aramendi T, Fernandez-Acenero MJ, Villanueva MC. Carcinosarcoma of the colon: report of a rare tumor. Pathol Res Pract 2003; 199:345-8.

20. Macaigne G, Aouad K, Boivin JF, Bellaïche A, Auriault ML, Picard D, et al. Sarcomatoid carcinoma of the colon: report of a case and review of the literature. Gastroenterol Clin Biol 2004;28:600-4.

21. Kim N, Luchs JS, Halpern D, Davis E, Donovan V, Weston SR, et al. Radiology-Pathology Conference: carcinosarcoma of the colon. Clin Imaging 2005;29:259-62.

22. Ambrosini-Spaltro A, Vaira V, Braidotti P, Rovati MP, Ferrero S, Bosari S. Carcinosarcoma of the colon: report of a case with morphological, ultrastructural and molecular analysis. BMC Cancer 2006;6:185.

23. Tsekouras DK, Katsaragakis S, Theodorou D, Kafiri G, Archontovasilis F, Giannopoulos P, et al. Rectal carcinosarcoma: a case report and review of literature. World J Gastroenterol 2006;12: 1481-4.

24. Ozturk E, Yilmazlar T, Yerci O. A rare tumor located in the anorectal junction: sarcomatoid carcinoma. Turk J Gastroenterol 2006;17:236-9.

25. Jeong YJ, Lee MR, Kim JC, Hwang PH, Moon WS, Chung MJ. Carcinosarcoma of the rectosigmoid colon in a 13-year-old girl. Pathol Int 2008;58:445-50.

26. Patel DH, Dang S, Bentley FR, Julka RN, Olden KW, Aduli F. Carcinosarcoma of the colon: a rare cause of colovesical fistula. Am Surg 2009;75:335-7.

27. Delahunt B, Eble JN, Nacey JN, Grebe SK. Sarcomatoid carcinoma of the prostate: progression from adenocarcinoma is associated with p53 over-expression. Anticancer Res 1999;19:4279-83.

28. Guarino M, Tricomi P, Giordano F, Cristofori E. Sarcomatoid carcinomas: pathological and histopathogenetic considerations. Pathology 1996;28:298-305. 